\title{
Polymer Nanoparticles Prepared by Supercritical Carbon Dioxide for in Vivo Anti-cancer Drug Delivery
}

\author{
Maofang Hua ${ }^{1}$, Xiufu Hua ${ }^{2, *}$
}

(Received 19 October; accepted 08 November 2013; published online 30 December 2013)

\begin{abstract}
A new approach for producing polymer nanoparticles made of bovine serum albumin-poly(methyl methacrylate) conjugate by precipitating in supercritical $\mathrm{CO}_{2}$ is reported. The nanoparticles were loaded with the anti-tumor drug camptothecin. With albumin serving as a nutrient to cells, the drug-encapsulated nanoparticle shows an enhanced ability to kill cancer cells compared to that of the free drug in solution both in vitro and in vivo.
\end{abstract}

Keywords: Protein; Polymer; Nanoparticle; Drug delivery

Citation: Maofang Hua and Xiufu Hua, "Polymer Nanoparticles Prepared by Supercritical Carbon Dioxide for in Vivo Anti-cancer Drug Delivery", Nano-Micro Lett. 6(1), 20-23 (2014). http://dx.doi.org/10.5101/ $\mathrm{nml} \cdot \mathrm{v} 6 \mathrm{i1} \cdot \mathrm{p} 20-23$

\section{Introduction}

Polymeric nanoparticles have much medical promise with a large number of therapeutic nanoparticles presently in clinical trials or approved for clinical use [1-4]. Ge et al. [5] developed a new type of protein-polymer hybrid nanoparticles made of hydrophilic denatured bovine serum albumin (BSA) covalently bonded to hydrophobic poly(methyl methacrylate) (PMMA).

Based on their study, here we report a new approach for producing such nanoparticles made of bovine serum albumin-poly(methyl methacrylate) conjugate by precipitating in supercritical $\mathrm{CO}_{2}$. BSA-PMMA nanoparticles can be prepared with hydrophobic drugs being encapsulated by a simple precipitation using supercritical carbon dioxide $\left(\mathrm{SC}-\mathrm{CO}_{2}\right)$ as an anti-solvent. $\mathrm{SC}-\mathrm{CO}_{2}$ is also non-toxic, non-flammable, and FDA approved. Such a process can readily be scaled to kilogram quantities, and represents a new approach with great potential to produce dry polymeric nanoparticles for sus- tained drug delivery [6]. In this work we use the solution enhanced dispersion by supercritical fluids (SEDS) method to produce camptothecin (CPT)-encapsulated BSA-PMMA nanoparticles. The nanoparticle shows an enhanced ability to kill cancer cells compared to that of the free drug in solution both in vitro and in vivo.

The BSA-PMMA conjugate was synthesized by the method described by Ge et al. previously [5]. In a typical experiment, BSA (lyophilized powder, from SigmaAldrich) was dissolved in dimethyl sulfoxide (DMSO) at $50^{\circ} \mathrm{C}$ at a concentration of $2 \mathrm{mg} / \mathrm{mL}$, followed by addition of acrylic acid N-hydroxysuccinimide ester (NAS) (in DMSO at a concentration of $20 \mathrm{mg} / \mathrm{mL}$ ) with a molar ratio of NAS to BSA of 130:1. After reaction at $25^{\circ} \mathrm{C}$ for 5 hours, methyl methacrylate (MMA) was added, followed by addition of 2,2'azobis(2-methylpropionitrile) (AIBN) $(8 \mathrm{mM})$ to initiate the polymerization at $70^{\circ} \mathrm{C}$. The conjugate was collected by precipitation in a methanol/ethyl ether $(1: 8, \mathrm{v} / \mathrm{v})$ mixture. The BSA:PMMA weight ratio in the conjugate was determined as $\sim 4: 1$ by ${ }^{1} \mathrm{H}-\mathrm{NMR}$.

\footnotetext{
${ }^{1}$ Lianyungang Maternal and Child Health Hospital, Lianyungang 222006, China

${ }^{2}$ Department of Scientific Research and Development, Tsinghua University, Beijing 100084, China

*Corresponding author. E-mail: hua_xiufu@163.com
} 
Then, $2 \mathrm{mg} / \mathrm{mL}$ of BSA-PMMA conjugate and 0.25 $\mathrm{mg} / \mathrm{mL}$ of CPT were dissolved in chloroform, followed by subjecting to the SEDS process. Briefly, the solution was injected $(1 \mathrm{~mL} / \mathrm{min})$ through a nozzle with $250 \mu \mathrm{m}$ internal diameter into a $\mathrm{SC}-\mathrm{CO}_{2}(150 \mathrm{~g} / \mathrm{min})$ at $40^{\circ} \mathrm{C}$ and 100 bar. CPT is used for treating a wide range of tumors [7]. However, it is poorly soluble in water [8]. After preparing the CPT-encapsulated BSA-PMMA nanoparticles by precipitating in $\mathrm{SC}-\mathrm{CO}_{2}$ (Fig. 1(a)), we estimated the yield of our SEDS process to be $\sim 88 \%$. The scanning electron microcopy (SEM) image (Fig. 1(b)) shows the nanoparticles have an average size around 200 300 nm. The size of CPT-loaded BSA-PMMA nanoparticles dispersed in PBS (pH 7.4) at a concentration of $7 \mathrm{mg} / \mathrm{mL}$ was measured to be 310 $\mathrm{nm}(\mathrm{PDI}=0.121)$ by dynamic light scattering (mean size: $310 \mathrm{~nm}$, size distribution: $\pm 27 \mathrm{~nm}$ ).

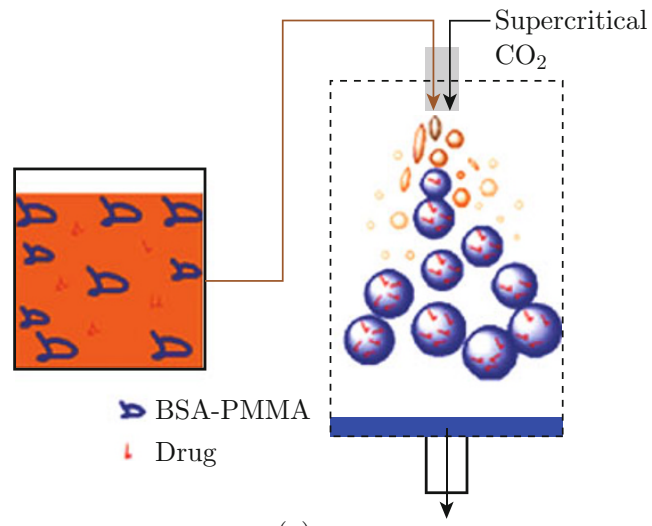

(a)

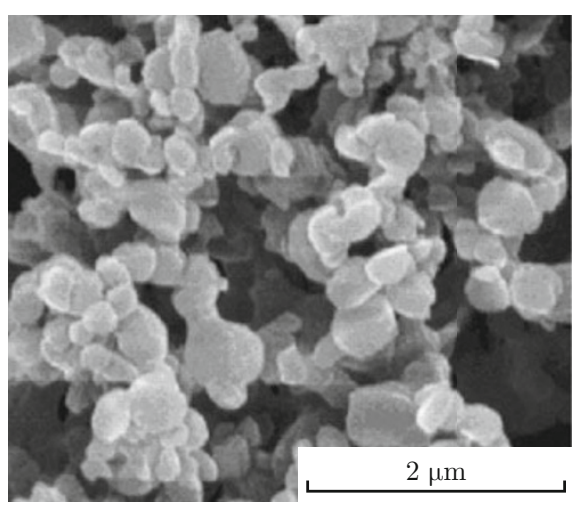

(b)

Fig. 1 (a) Preparation of drug-loaded nanoparticles by precipitation in $\mathrm{SC}-\mathrm{CO}_{2}$; (b) SEM image of BSA-PMMA nanparticles.

The drug loading was determined as $12.5 \mathrm{wt} \%$ in the BSA-PMMA nanoparticles. The drug release profile was studied by dispersing the CPT-loaded nanoparticles in a release medium (PBS, pH 7.4 containing 2\% $(\mathrm{w} / \mathrm{v})$ Tween 80) [9]. As shown in Fig. 2(a), at the drug loading ratio of $12.5 \mathrm{wt} \%$, the encapsulated CPT was released from the nanoparticles over a period of 48 hours with a low initial burst. And the encapsulation ratio was determined to be $\sim 10 \mathrm{wt} \%$. At the early stage of drug release, the diffusion of $\mathrm{CPT}$ from nanoparticles probably played an important role and resulted in a burst release. At the late stage, the degradation of BSA-PMMA nanoparticles caused more drug molecules to gradually be released.
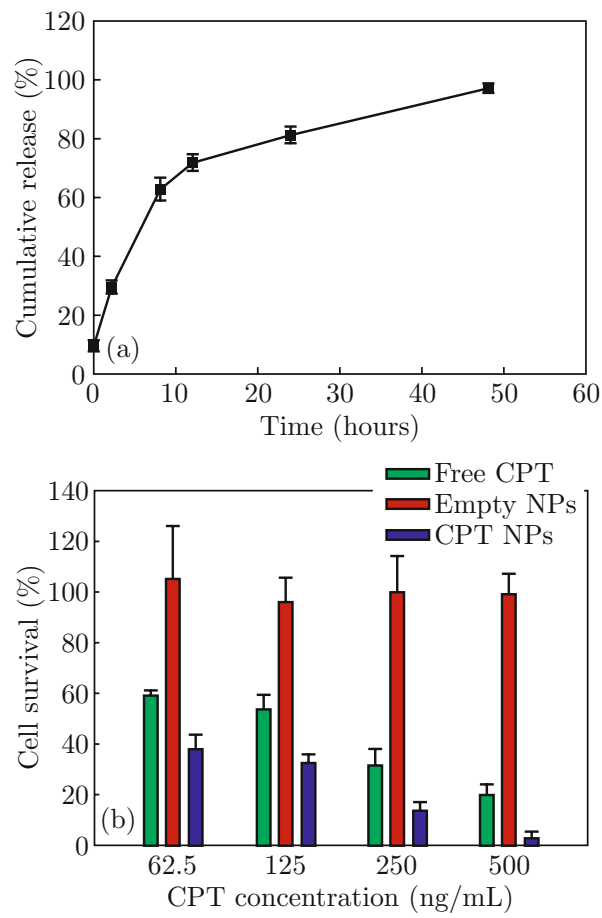

Fig. 2 (a) Sustained release of CPT from nanoparticles; (b) In vitro anti-cancer activities of free $\mathrm{CPT}$ and $\mathrm{CPT}$ nanoparticles.

The CPT-encapsulated BSA-PMMA nanoparticles were analyzed for their ability to retard the proliferation of tumor cells. Human colorectal cancer cells HCT116 were plated in 96-well microplates at $5.0 \times$ $10^{3}$ cells per well in $190.0 \mu \mathrm{L}$ of complete medium and allowed to adhere under incubation at $37^{\circ} \mathrm{C}$ and $5 \%$ $\mathrm{CO}_{2}$. Twenty-four hours later, HCT116 cells were exposed to CPT in a $10 \% \mathrm{v} / \mathrm{v}$ DMSO solution containing CPT or CPT-encapsulated nanoparticles with the same drug concentration. The final concentration of DMSO in the cell culture medium was $0.5 \%(\mathrm{v} / \mathrm{v})$, which had no measurable effect on cell viability. Empty nanoparticles were used as a control. The viability of cell populations was then assessed by the MTT method [10] at 72 h. As shown in Fig. 2(b), the dose-dependent cytotoxic effect of the CPT solution was evident cumulating in more than $50 \%$ HCT116 survival at $62.5 \mathrm{ng} / \mathrm{mL}$ after $72 \mathrm{~h}$. The encapsulation of CPT into the nanoparticles resulted in marked improvements of the anti-tumor activities. After $72 \mathrm{~h}$, less than $10 \%$ survival was observed at the CPT concentration above $250 \mathrm{ng} / \mathrm{mL}$. Calculated from the experiment, the IC50 for free CPT was around 
$87.5 \mathrm{ng} / \mathrm{mL}$, while the IC50 for CPT in nanoparticles was only around $23.5 \mathrm{ng} / \mathrm{mL}$. The empty nanoparticles showed excellent biocompatibility. Around $100 \%$ cell survival was observed for cells treated with different concentrations of empty nanoparticles.

We tested the in vivo anti-tumor efficiency of CPTencapsulated BSA-PMMA nanoparticles by i.v. injection into mice with subcutaneous colon cancer tumors. NOG (NOD/LtSz-scid IL2R $\gamma$ null) mice (15-16 weeks old) were injected s.c. with $2 \times 10^{7}$ HCT116 colon cancer cells approximately 10-18 days before dosing. Tumor sizes were measured for the duration of the experiment. Treatment was initialized when the mean tumor size reached approximately $300-500 \mathrm{~mm}^{3}$ (day 1). The animals were sorted into 2 groups, each group having six mice. For group one, as the positive control, free CPT was administered by intraperitoneal injection (i.p. injection). The dose of CPT $(9 \mathrm{mg} / \mathrm{kg})$ was based on the literature [11]. CPT is very insoluble in aqueous solution and is acutely lethal when given to mice by i.v. injection at $9 \mathrm{mg} / \mathrm{kg}(0.18 \mathrm{mg} / 20 \mathrm{~g}$ mouse) due to the particulate matter in the drug suspension. Thus, we followed the previous protocol [11] for the administration of free CPT. In the experiment, the CPT was suspended in a vehicle of $0.5 \%$ methylcellulose and $0.1 \%$ Tween 80 and administered by i.p. injection as an attempt to maximize its efficiency. Mice were given CPT at $9 \mathrm{mg} / \mathrm{kg}$ once daily on day 1 and 7 with a dosing volume of $200 \mu \mathrm{L}$. For group two, mice were treated with CPT nanoparticles. The dry powder of CPT nanoparticles was suspended in PBS $(\mathrm{pH}$ 7.4) at a concentration of $7 \mathrm{mg} / \mathrm{mL}$ with the assistance of probe sonication. The nanoparticles showed excellent dispersability in aqueous solution because of the hydrophilic shell of BSA on the nanoparticles. The treatment was administered intravenously by tail vein injection (i.v. injection) once daily on day 1 and 7 at 9 $\mathrm{mg}$ of $\mathrm{CPT} / \mathrm{kg}$. The small size and narrow size distribution of the nanoparticles in PBS (pH 7.4) made this formulation very suitable for i.v. injection. As shown in Fig. 3, the tumor volume in CPT nanoparticle-treated mice was significantly smaller than that of mice treated with free CPT. At day 30, the median tumor volume of the CPT nanoparticle-treated mice is $448 \mathrm{~mm}^{3}$, which is almost the same compared with the tumor volume at day $1\left(437 \mathrm{~mm}^{3}\right)$. However, for free CPT-treated group, at day 30 , the median tumor volume $3515 \mathrm{~mm}^{3}$, which is 7 times increased compared with the tumor volume at day 1. Thus, a significant prohibition of tumor growth was observed when using CPT encapsulated nanoparticles compared with free CPT.

PMMA is biocompatible but not biodegradable in vivo. In our study, we choose the PMMA as the hydrophobic core of the BSA-PMMA nanoparitcle is because of its good biocompatibility and the hydrophobicity which could be used to encapsulate hydrophobic

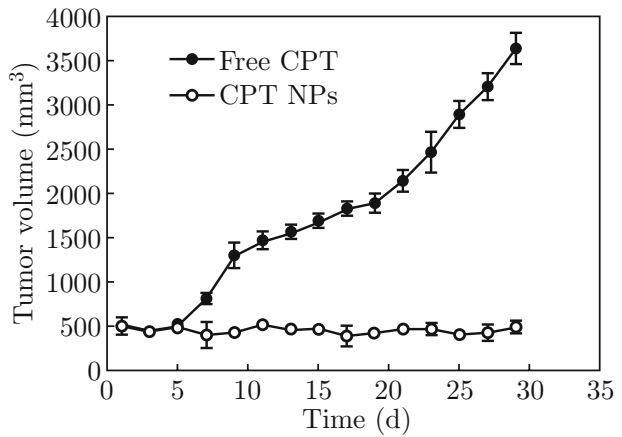

Fig. 3 In vivo anti-tumor efficiency of free CPT and CPTencapsulated BSA-PMMA nanoparticles.

drugs. A number of studies have tried to develop PMMA-based nanoparticles for drug delivery [12]. No obvious toxicity was observed by i.v. injection of PMMA nanoparticles in vivo [13]. In our study we utilized the BSA which is biodegradable to copolymerize with PMMA. One BSA molecule was covalently bound with about 49 PMMA chains. Each single PMMA chain attached only has 5-7 of repeating units (MMA) in the BSA-PMMA conjugate we used for in vivo study. After the degradation of BSA in vivo, only oligomers of MMA (5-7 of repeating units with 500-700 Da in molecular weight) would exist. In the in vitro and in vivo study, we observed that empty BSA-PMMA nanoparticles have good biocompatibility and no toxicity to cells or mice.

In summary, we have developed a new method to produce protein-polymer hybrid nanoparticles for anticancer drug delivery. We have demonstrated that the hybrid nanoparticles prepared by precipitating in SC$\mathrm{CO}_{2}$ have excellent biocompatibility and efficient cell uptake. The preparation process is simple and easy to scale up. As an example of this type of drug delivery vehicles, compared with free drug formulation, the camptothecin-encapsulated BSA-PMMA nanoparticles shows enhanced anti-tumor activity both in vitro and in animals.

\section{Acknowledgements}

The authors gratefully acknowledge the assistance provided by Post Dr. Junfeng Hui (Department of Chemistry, Tsinghua University) with the SEM images experiments.

\section{References}

[1] L. Zhang, F. Gu, J. Chan, A. Wang, R. S. Langer and O. C. Farokhzad, "Nanoparticles in medicine: therapeutic applications and developments", Clin. Pharmacol. Ther. 83(5), 761-769 (2008). http://dx.doi.org/ $10.1038 / \mathrm{sj}$. clpt. 6100400 
[2] R. Wang, Y. Zhang, D. Lu, J. Ge, Z. Liu and R. N. Zare, "Functional protein-organic/inorganic hybrid nanomaterials", WIERs: Nanomed. Nanobiotech. 5(4), 320-328 (2013). http://dx.doi.org/10.1002/ wnan. 1210

[3] J. Ge, E. Neofytou, J. Lei, R. E. Beygui and R. N. Zare, "Protein-polymer hybrid nanoparticles for drug delivery", Small 8(23), 3573-3578 (2012). http://dx. doi.org/10.1002/smll. 201200889

[4] J. Ge, E. Neofytou, T. J. Cahill III, R. E. Beygui and R. N. Zare, "Drug release from electric-fieldresponsive nanoparticles", ACS Nano 6(1), 227-233 (2012). http://dx.doi.org/10.1021/nn203430m

[5] J. Ge, J. Lei and R. N. Zare, "Bovine serum albumin-poly(methyl methacrylate) nanoparticles: an example of frustrated phase separation", Nano Lett. 11(6), 2551-2554 (2011). http://dx.doi.org/10. $1021 / \mathrm{nl} 201303 \mathrm{q}$

[6] J. Ge, G. B. Jacobson, T. Lobovkina, K. Holmberg and R. N. Zare, "Sustained release of nucleic acids from polymeric nanoparticles using microemulsion precipitation in supercritical carbon dioxide", Chem. Comm. 46(47), 9034-9036 (2010). http://dx. doi.org/10.1039/c0cc04258g

[7] B. C. Giovanella, J. S. Stehlin, M. E. Wall, M. C. Wani, A. W. Nicholas, L. F. Liu, R. Silber and M. Potmesil, "DNA topoisomerase I-targeted chemotherapy of human colon cancer in xenografts", Science 246(4933), 1046-1048 (1989). http://dx.doi.org/10. $1126 /$ science. 2555920
[8] B. Ertl, P. Platzer, M. Wirth and F. Gabor, "Poly(D,L-lactic-co-glycolic acid) microspheres for sustained delivery and stabilization of camptothecin", J. Controlled Release 61(3), 305-317 (1999). http:// dx. doi .org/10.1016/S0168-3659(99)00122-4

[9] C. L. Dora, M. Alvarez-Silva, A. G. Trentin, T. J. de Faria, D. Fernandes, R. da Costa, M. Stimamiglio and E. Lemos-Senna, "Evaluation of antimetastatic activity and systemic toxicity of camptothecinloaded microspheres in mice injected with B16F10 melanoma cells", J. Pharm. Pharm. Sci. 9(1), 22-31 (2006). http://www.ualberta.ca/\$ \im\$csps/ JPPS9 (1)/Senna.E/B16-F10.htm

[10] M. Ferrari, M. C. Fornasiero and A. M. Isetta, "MTT colorimetric assay for testing macrophage cytotoxic activity in vitro", J. Immunol. Methods 131(2), 165-172 (1990). http://dx.doi.org/10.1016/ 0022-1759 (90) 90187-Z

[11] J. Cheng, K. T. Khin and M. E. Davis, "Antitumor activity of beta-cyclodextrin polymer-camptothecin conjugates", Mol. Pharm. 1(3), 183-193 (2004). http:// dx.doi.org/10.1021/mp049966y

[12] A. Bettencourt and A. J. Almeida, "Poly(methyl methacrylate) particulate carriers in drug delivery", J. Microencapsulation 29(4), 353-367 (2012). http:// dx.doi.org/10.3109/02652048.2011.651500

[13] C. Passirani, G. Barratt, J. P. Devissaguet and D. Labarre, "Long-circulating nanoparticles bearing heparin or dextran covalently bound to poly(methyl methacrylate)", Pharm. Res. 15(7), 1046-1050 (1998). http://dx.doi.org/10.1023/A: 1011930127562 